\title{
Laser-fired contact optimization in c-Si solar cells
}

\author{
P. Ortega ${ }^{1 *}$, A. Orpella ${ }^{1}$, I. Martín ${ }^{1}$, M. Colina ${ }^{1}$, G. López ${ }^{1}$, C. Voz ${ }^{1}$, M. I. Sánchez ${ }^{2 \dagger}$, \\ C. Molpeceres ${ }^{2}$ and R. Alcubilla ${ }^{1}$ \\ ${ }^{1}$ Departament d'Enginyeria Electrònica, Universitat Politècnica de Catalunya UPC, C/Jordi Girona 1-3, Mòdul C4, 08034 Barcelona, \\ Spain \\ ${ }^{2}$ Centro Láser UPM, Universidad Politécnica de Madrid, Ctra de Valencia Km 7.3, 28031, Madrid, Spain
}

\begin{abstract}
In this work we study the optimization of laser-fired contact (LFC) processing parameters, namely laser power and number of pulses, based on the electrical resistance measurement of an aluminum single LFC point. LFC process has been made through four passivation layers that are typically used in c-Si and mc-Si solar cell fabrication: thermally grown silicon oxide $\left(\mathrm{SiO}_{2}\right)$, deposited phosphorus-doped amorphous silicon carbide $(\mathrm{a}-\mathrm{SiC} \times \mathrm{H}(n))$, aluminum oxide $\left(\mathrm{Al}_{2} \mathrm{O}_{3}\right)$ and silicon nitride $\left(\mathrm{SiN}_{x} / \mathrm{H}\right)$ films. Values for the LFC resistance normalized by the laser spot area in the range of $0.65-3 \mathrm{~m} \Omega \mathrm{cm}^{2}$ have been obtained.
\end{abstract}

\section{KEYWORDS}

laser-fired contact; passivation layer; PERC solar cell; specific contact resistance; spreading resistance

\section{* Correspondence}

P. Ortega, Departament d'Enginyeria Electrònica, Universitat Politècnica de Catalunya UPC C/ Jordi Girona 1-3, Mòdul C4, 08034 Barcelona, Spain. Tel: +34934054193; Fax: +34934016756

E-mail: ortega@eel.upc.edu

\section{INTRODUCTION}

In the last years laser processing has been focussing the interest of the PV industry. Laser scribing for thin film solar cell isolation [1] and laser etch in crystalline solar cells $[2,3]$ are nowadays industrial realities.

The use of laser to create ohmic contacts between metal films and silicon was already explored in 1976 within the microelectronic industry [4]. Surprisingly, its application in photovoltaics to contact aluminum with p-type silicon, so-called laser-fired contacts (LFC), was not reported until 2002 [5]. In the LFC process, a laser beam fires the aluminum through a dielectric passivation layer into the silicon wafer to form the electrical contact to the silicon bulk. This laser technique is an interesting alternative for the fabrication of both laboratory and industrial scale high efficiency passivated emitter and rear cell (PERC) c-Si solar cells by combining simple wafer handling and high throughput capacity without the necessity of photolithography. In addition, LFC process is a room temperature process-avoiding wafer warping [6] that has becoming a major drawback due to the combination of thin wafers and high temperature firing of screen-printed pastes.

From an electrical point of view, another advantage is the possibility to create $\mathrm{p}+$ doped regions under the contacts improving their electrical performance. As a result, low specific contact resistance can be achieved independently of substrate resistivity. Furthermore, the formation of this $\mathrm{p}+$ region creates a local back surface field (BSF) decreasing carrier recombination at the contacted surface [7]. These two features allow the fabrication of high efficient solar cells from a wide range of substrate resistivities as reported in Ref. [8] where 21.6 $19.5 \%$ efficient solar cells were obtained in FZ wafers with resistivities ranging from 0.5 to $100 \Omega \mathrm{cm}$, respectively. Additionally, LFC can be combined with many different rear-passivating dielectrics. In Ref. [9] three different passivating configurations are used: a stack of PECVD amorphous silicon and silicon oxide layers, an amorphous silicon carbide film and a triple stack of silicon oxide and silicon nitride. In all three cases solar cells with efficiencies beyond $20 \%$ have been obtained.

Finally, the laser firing concept has been extended to fabricate local emitters in solar cells. In this case, the laser beam hits a dopant containing layer, which is of the 
opposite type than the substrate, e.g., in n-type substrates using the aluminum metal layer as a dopant source [10] or performing the laser firing through a phosphorus doped passivation layer on p-type wafers [11].

In this paper, we focus on the determination of laser parameters to optimize contact resistance through different dielectric films that have demonstrated excellent c-Si passivating properties: thermal $\mathrm{SiO}_{2}$ [12], silicon nitride [13], silicon carbide [14], and aluminum oxide [15]. It is well known that to obtain high efficiency solar cells using the LFC technique, in addition to good ohmic contacts, low recombination at the LFC points together with a geometrical optimization of the rear contact scheme are necessary. The optimization of these key factors is beyond the scope of this paper and a thorough study will be published elsewhere.

\section{LASER-FIRED CONTACT CHARACTERIZATION}

Electrical characterization of the LFC is performed by measuring the resistance of one contact, $R_{\mathrm{LFC}}$, as sketched in Figure 1, where $r$ is the radius of the contact, $\rho_{\mathrm{b}}$ the base resistivity, and $W$ is the wafer thickness.

In this structure the LFC point is done on the front surface through the passivation layer while the rear surface is totally covered with metal discarding additional ohmic losses at the back contact. Then, $R_{\mathrm{LFC}}$ can be calculated as the sum of two terms: the spreading resistance $R_{\mathrm{s}}$ and the contact resistance $R_{\mathrm{c}}$, being $R_{\mathrm{LFC}}=R_{\mathrm{S}}+R_{\mathrm{c}}$. The former represents the minimum value of the LFC resistance, related to current flow distribution throughout the $\mathrm{c}-\mathrm{Si}$ bulk, and can be calculated approximately as [16]

$$
R_{\mathrm{s}} \cong \frac{\rho_{\mathrm{b}}}{2 \pi r} \arctan \left(\frac{2 W}{r}\right)
$$

and the contact resistance is given by

$$
R_{\mathrm{c}}=\frac{\rho_{\text {cef }}}{\pi r^{2}}
$$

where $\rho_{\text {cef }}$ is the effective specific contact resistance considering that all the surface of the LFC point is contacted. Notice that $\rho_{\text {cef }}$ can be much higher than values typically found in aluminum contacts doped near the solubility limit $\left(\sim 10^{-6} \Omega \mathrm{cm}^{2}\right)$, because this parameter

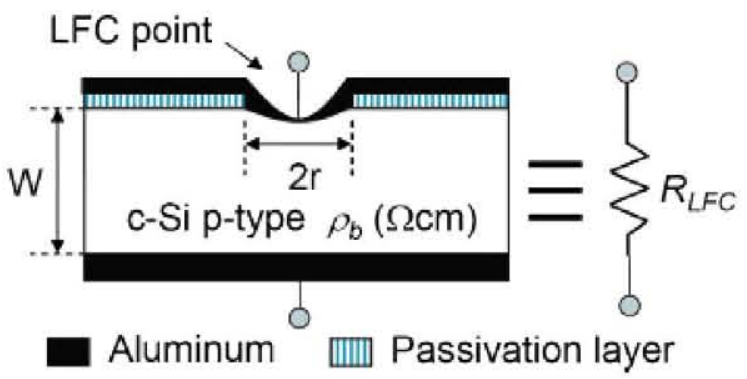

Figure 1. Test structure cross section. also includes resistive losses in the current flow from the inner part of the LFC point to the surrounding metal. We can normalize the LFC resistance $R_{\mathrm{LFC}}$ considering the spot area by means of the specific LFC resistance $r_{\text {LFC }}$ in $\Omega \mathrm{cm}^{2}$ units, then

$$
r_{\mathrm{LFC}}=R_{\mathrm{LFC}} \times \pi r^{2}=\frac{\rho_{\mathrm{b}} r}{2} \arctan \left(\frac{2 W}{r}\right)+\rho_{\text {cef }}
$$

It can be pointed out that $r_{\text {LFC }}$ not only depends on the quality of the contact but also depends on $\rho_{\mathrm{b}}$ and $r$. In a well-contacted point $\left(\rho_{\text {cef }} \cong 0\right) r_{\text {LFC }}$ reaches the specific spreading resistance limit $r_{\mathrm{s}}\left(R_{\mathrm{s}} \times \pi r^{2}\right)$, i.e., $r_{\mathrm{LFC}} \cong r_{\mathrm{s}}$, resulting in $r_{\mathrm{LFC}}$ directly proportional to $\rho_{\mathrm{b}}$ and $r$. As a consequence, for low enough $\rho_{\text {cef }}$, substrate resistivity and the size of the LFC determine the total value of the measured resistance.

The measurement done on a single LFC point can be easily extrapolated in order to calculate the series resistance of a square array of LFCs. The array consists of $N$ LFC points separated one to each other a distance or pitch, $p$, resulting in an array area of $(p \sqrt{N}) \times(p \sqrt{N})$ (see Figure 2). Therefore, as a first approach, the normalized array resistance, $r_{\mathrm{a}}$ in $\Omega \mathrm{cm}^{2}$, can be calculated from the equivalent resistance of $N$ identical $R_{\text {LFC }}$ resistances connected in parallel, assuming that each contact is electrically independent from the others, i.e., contacts are sufficiently separated from each other. Then:

$$
r_{\mathrm{a}} \simeq \frac{R_{\mathrm{LFC}}}{N} \times(p \sqrt{N})^{2}=R_{\mathrm{LFC}} p^{2}
$$

It is important to underline that $r_{\mathrm{a}}$ is in fact the specific resistance related to the base of a LFC-PERC solar cell,

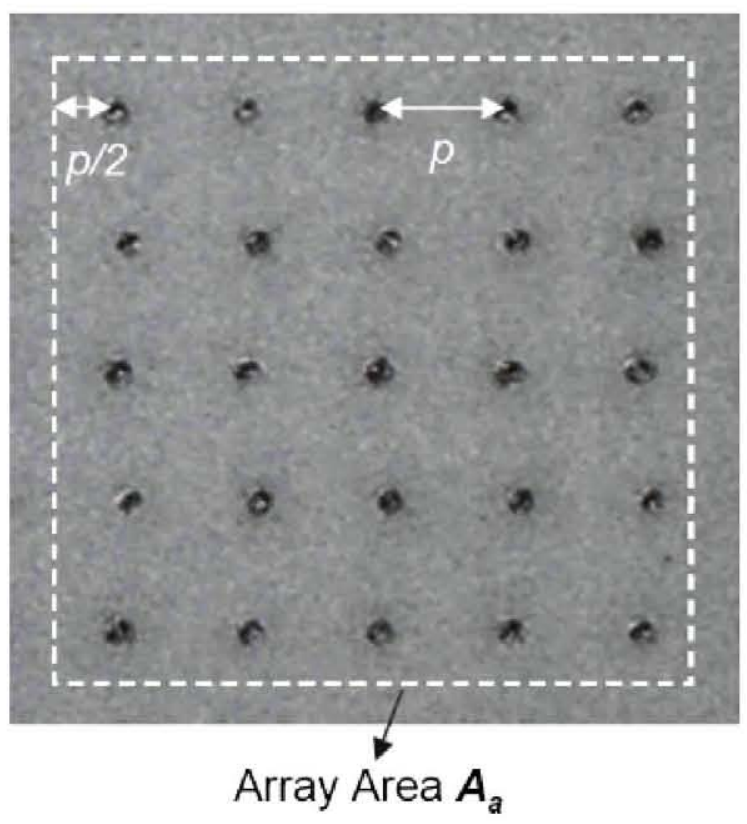

Figure 2. LFC array consisting of a square array with N LFC points ( $N=25$ in this case) separated one from other a distance or pitch $p$. 
assuming low injection at the maximum power point (MPP) where the fill factor (FF) and efficiency are calculated. From PC-1D simulations of solar cells working at 1 Sun with very low recombination losses, it can be concluded that changes in the resistivity due to conductivity modulation [17] can be neglected for p-type substrates with resistivities smaller than $\sim 5 \Omega \mathrm{cm}$ (wafers doping densities higher than $3 \times 10^{15} \mathrm{~cm}^{-3}$ ), i.e., carrier excess densities below base doping concentration.

Alternatively, Equation (4) can be expressed using the $r_{\text {LFC }}$ specific resistance and a typical design parameter of the rear contact grid of PERC solar cells as it is the contacted area fraction $f_{\mathrm{c}}$ defined as $f_{\mathrm{c}}=\pi r^{2} / p^{2}$, resulting in

$$
r_{\mathrm{a}} \cong \frac{r_{\mathrm{LFC}}}{f_{\mathrm{c}}}
$$

It is clear that small $r_{\mathrm{a}}$ values, for a fixed contacted area fraction $f_{\mathrm{c}}$, require decreasing $r_{\mathrm{LFC}}$. In the following sections we focus on the determination of laser parameters to minimize $r_{\mathrm{LFC}}$.

\section{EXPERIMENTAL AND LASER SPOT MORPHOLOGY}

To characterize the LFCs process, $280 \mu \mathrm{m}$-thick $0.45 \Omega \mathrm{cm}$ resistivity single side polished p-type $\mathrm{FZ} \mathrm{c}-\mathrm{Si}$ wafers have been used. Samples have different passivation dielectric layers: (i) thermally grown silicon oxide $\left(\mathrm{SiO}_{2}, 110 \mathrm{~nm}\right)$, (ii) phosphorus doped silicon carbide (a-SiC $x / \mathrm{H}(n)$, $80 \mathrm{~nm})$, (iii) silicon nitride $\left(\mathrm{a}-\mathrm{SiN}_{x} / \mathrm{H}, 70 \mathrm{~nm}\right)$, and (iv) aluminum oxide $\left(\mathrm{Al}_{2} \mathrm{O}_{3}, 50 \mathrm{~nm}\right)$. A commercial PECVD reactor (PlasmaLab DP-80, $13.56 \mathrm{MHz}$ ) was used to deposit the a-SiC $x / \mathrm{H}(n)$ and a-SiN ${ }_{x} / \mathrm{H}$ layers. $\mathrm{Al}_{2} \mathrm{O}_{3}$ films were deposited by Atomic Layer Deposition technique (Savannah S-300 Cambridge NanoTech). All material depositions were carried out only on the front surface of the wafers. In the samples with thermal $\mathrm{SiO}_{2}$, the rear surface oxide was stripped by wet etching protecting the front oxide. Next, a $2 \mu \mathrm{m}$ thick aluminum layer was deposited by sputtering on both faces in all cases. A forming gas anneal $\left(425^{\circ} \mathrm{C}, 15 \mathrm{~min}\right)$ was performed to ensure good ohmic rear contact. Then, isolated regions of aluminum $(5 \mathrm{~mm} \times 5 \mathrm{~mm}$ area) were defined by standard photolithography at the front side ready to be laser processed. The laser spot morphology was studied using optical microscopy (Optika B-600 MET), optical profilometry (Veeco Wyko 9800NT), and scanning electron microscopy (SEM; Zeiss Neon 40). Elemental material analysis was performed by energy dispersive X-ray spectroscopy (EDS). LFC resistance measurements were carried out using a four probe configuration to avoid ohmic losses in the wires.

The laser system used was a Q-switched Nd/YAG laser (StarMarK SMP 100II Rofin-Baassel), operating at a wavelength of $1064 \mathrm{~nm}$ with $100 \mathrm{~ns}$ pulse length. The pulse repetition frequency $f$ was always fixed to $8 \mathrm{kHz}$. The laser power, $P$, can be adjusted by varying the current of the lamp that pumps the Nd/YAG crystal from 1 to $12.6 \mathrm{~W}$ corresponding to pumping currents ranging from 16 to $25 \mathrm{~A}$, respectively. Laser power was measured by means of a power thermal sensor (OPHIR 30(150)A-BB-18). The laser beam is guided by a $x-y$ scan-head that allows to process samples up to $8 \mathrm{in}$. of diameter. Laser emits in the $\mathrm{TEM}_{00}$ mode with a Gaussian fluence distribution $F$. Hence

$$
F(d)=F_{\mathrm{o}} \mathrm{e}^{-2 d^{2} / \sigma^{2}}=\frac{2 P}{f \pi \sigma^{2}} \mathrm{e}^{-2 d^{2} / \sigma^{2}}
$$

where $d$ is the distance from the spot center, $F_{\mathrm{o}}$ is the maximum fluence in $\mathrm{J} / \mathrm{cm}^{2}$ that it is related to the laser power $P$, the frequency of the pulse train $f$, and the laser beam radius $\sigma(76 \mu \mathrm{m}$ in our case). A SEM image of a single LFC point is shown in Figure 3a (theoretical laser beam fluence is also shown in Figure $3 b$ ). In this case, laser power was adjusted to $P=2.5 \mathrm{~W}$ and 125 laser pulses were used.

As it can be seen in Figure 3 there are two boundaries that define two different regions: the inner crater, where the silicon is melted corresponding to fluence values higher than $\sim 2.7 \mathrm{~J} / \mathrm{cm}^{2}$; and a laser affected region (outer crater) for fluences beyond $\sim 1.7 \mathrm{~J} / \mathrm{cm}^{2}$. The former value suggests that to create the contact through a $110 \mathrm{~nm} \mathrm{SiO}$ layer a minimum laser power around $P \sim 2 \mathrm{~W}$ is required.

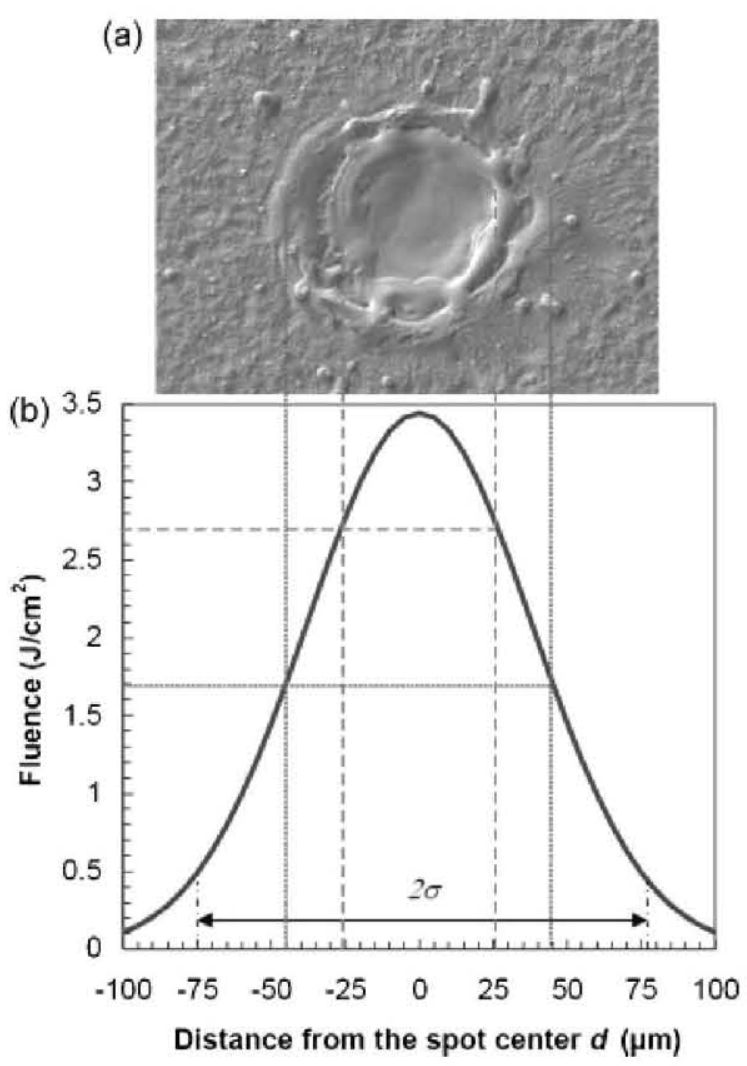

Figure 3. (a) SEM image of the footprint in the silicon once LFC is performed through a $110 \mathrm{~nm} \mathrm{\textrm {SiO } _ { 2 }}$ layer $(P=2.5 \mathrm{~W}, 125$ pulses). (b) Theoretical laser spot fluence $F$. 


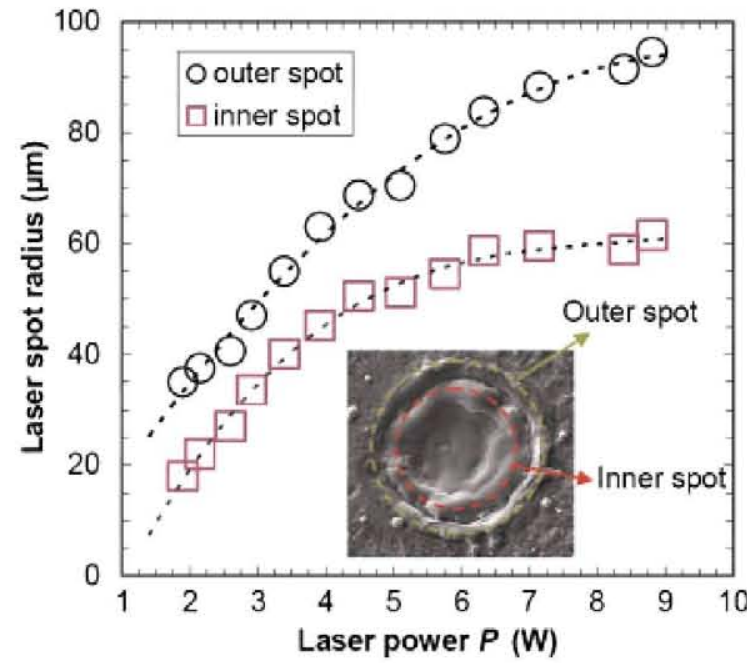

Figure 4. Spot radius of the inner and outer crater versus laser power. LFC points were made through a $110 \mathrm{~nm} \mathrm{SiO} 2$ layer using 125 pulses.

Changing the laser power allows controlling the crater size on the c-Si. The dependence of the spot radius when laser power varies from 2 to $9 \mathrm{~W}$ is shown in Figure 4. It increases from 35 to $95 \mu \mathrm{m}$ (outer crater) and 20 to $60 \mu \mathrm{m}$ (inner crater), respectively.

Figure 5 shows the dependence of the crater depth with the number of laser pulses $N_{\mathrm{p}}$ for four representative values of laser power. For a same number of pulses, crater depth depends strongly on the laser power. Thus, the higher the laser power the deeper the crater depth. On the other hand, the depth dependence with the number of pulses exhibits a saturation behavior from a minimum amount of pulses that

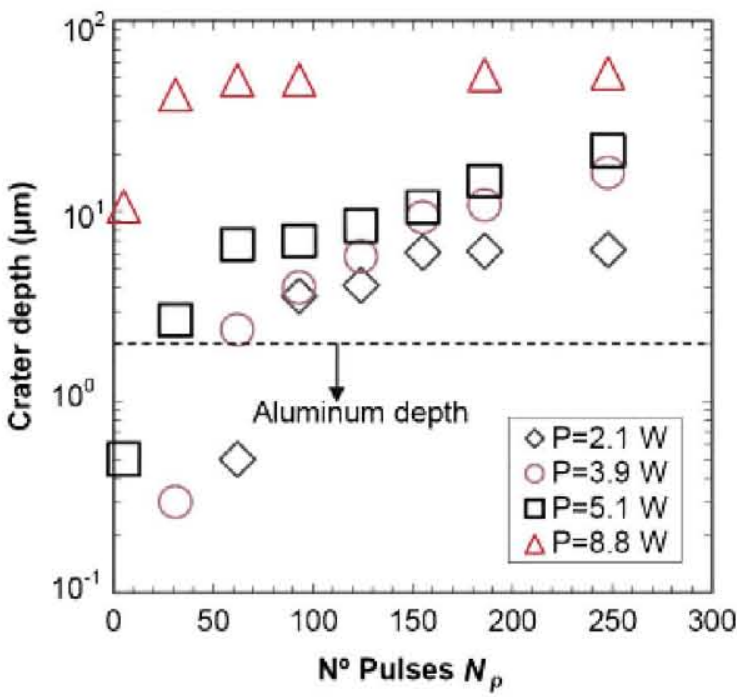

Figure 5. Total crater depth through a $110 \mathrm{~nm}$ thermal $\mathrm{SiO}_{2}$ layer versus $N_{0}$ for several laser powers. A dashed line was also included in the graph indicating the $2 \mu \mathrm{m}$ aluminum thickness as a reference. also depends on the laser power. Indeed, this minimum quantity of pulses is increased as the laser power is decreased. In that sense, if we use a $5.1 \mathrm{~W}$ laser power a crater depth of about $2 \mu \mathrm{m}$ is obtained with 30 pulses, while for a laser power of $2.1 \mathrm{~W}, 100$ pulses are required to obtain the same crater depth.

\section{ELECTRICAL RESULTS AND DISCUSSION}

As discussed in Section 2, we used a single point structure to electrically optimize the LFC through four different passivating dielectrics: thermal $\mathrm{SiO}_{2}, \mathrm{a}-\mathrm{SiC} x / \mathrm{H}(n), \mathrm{a}-\mathrm{SiN}_{x}$ and $\mathrm{Al}_{2} \mathrm{O}_{3}$. The dependence of $R_{\mathrm{LFC}}$ on laser power for different number of laser pulses $N_{\mathrm{p}}(5-250)$, for the case of thermal $\mathrm{SiO}_{2}$, is shown in Figure 6. The spreading resistance, considering the inner and the outer crater as contacted area, is also plotted.

As it can be seen in Figure $6, R_{\mathrm{LFC}}$ values are very close to the spreading resistance limit for laser powers lower than $\sim 6 \mathrm{~W}$ if the inner crater is considered as the contacted region. This would mean that in most cases the quality of the ohmic contact is good enough and $R_{\mathrm{LFC}}$ is dominated by the spreading resistance, i.e., $R_{\mathrm{LFC}} \simeq R_{\mathrm{s}}$, and, thus, $R_{\mathrm{LFC}}$ would be proportional to base resistivity (see Equation (1)). A comparison of $R_{\mathrm{LFC}}$ values normalized to the bulk resistivity, $R_{\mathrm{LFC}} / \rho_{\mathrm{b}}$, for 2 and $0.45 \Omega \mathrm{cm}$ resistivity substrates is shown in the inset of Figure 6. Normalized values are very similar confirming that $R_{\mathrm{LFC}}$ resistance is practically dominated by the spreading term and that the

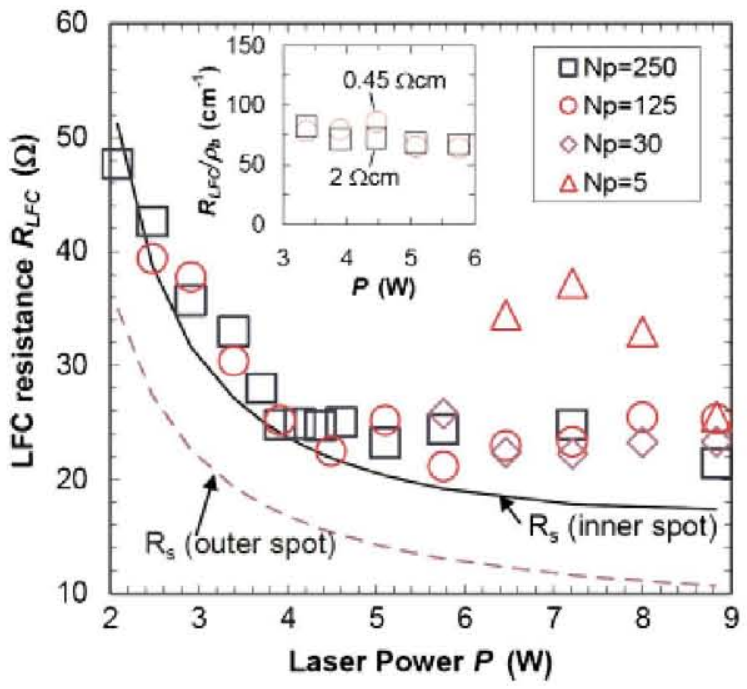

Figure 6. $R_{\mathrm{LFC}}$ versus laser power $P$ for several $N_{\mathrm{p}}(5,30,125$, and 250 pulses). Hundred nanometers of thermal $\mathrm{SiO}_{2}$ is used as a passivation layer. The spreading limit considering the inner spot (continuous line) and the outer spot (dashed line) are also included in the graph. A comparison of the normalized $R_{\mathrm{LF}} / \rho_{\mathrm{b}}$ resistance versus $P$ for two material resistivities 0.45 and $2 \Omega \mathrm{cm}$ ( $N_{p}=125$ pulses) is shown in the inset. 
inner crater is the contacted area. This conclusion is in concordance with the results reported in Ref. [8]. For higher laser powers $(>\sim 6 \mathrm{~W}), R_{\mathrm{LFC}}$ diverts from the spreading limit suggesting that electrical contacted area is smaller than the whole inner crater. This could be attributed to a more abrupt surface profile as will be discussed later.

Once the contacted area is defined, we can calculate the specific LFC resistance of each contact point, $r_{\text {LFC }}$. Figure 7 shows the behavior of the $r_{\mathrm{LFC}}$ in the laser power range $2-6 \mathrm{~W}$. The specific spreading resistance $r_{\mathrm{s}}$, considering the inner crater radius, is also shown in the graph (dashed line). The study is done for $\mathrm{SiO}_{2}$ passivation layer and extended to the other dielectric materials.

As it can be seen in Figure 7, $r_{\text {LFC }}$ monotonically decreases following the trend of the spreading limit $r_{s}$, i.e., the contact resistance is much lower than spreading resistance. In this case, the only way to continue decreasing the LFC resistance, and then the array resistance $r_{a}$ - see equation (5) - keeping constant $f_{c}$, is reducing the inner laser spot radius with a shorter distance between LFC points (lower pitch). This goal can be achieved lowering the laser power until the laser beam reaches the minimum fluence to perform the contact. Best $r_{\text {LFC }}$ values about $0.65 \mathrm{~m} \Omega \mathrm{cm}^{2}$ are obtained for laser powers in the $2-3 \mathrm{~W}$ range, being the inner crater radius around $25 \mu \mathrm{m}$ (see Figure 4).

In the case of the silicon carbide layers, a $r_{\mathrm{LFC}}$ of about $3 \mathrm{~m} \Omega \mathrm{cm}^{2}$ can be achieved, appearing a minimum laser power around $\sim 5 \mathrm{~W}$ to perform a good LFC contact. This difference could be attributed to a higher thermal stability of the silicon - carbon bonds. In addition, there could be a phosphorus diffusion from the $\mathrm{a}_{-} \mathrm{SiC}_{x} / \mathrm{H}(n)$ film into the c-

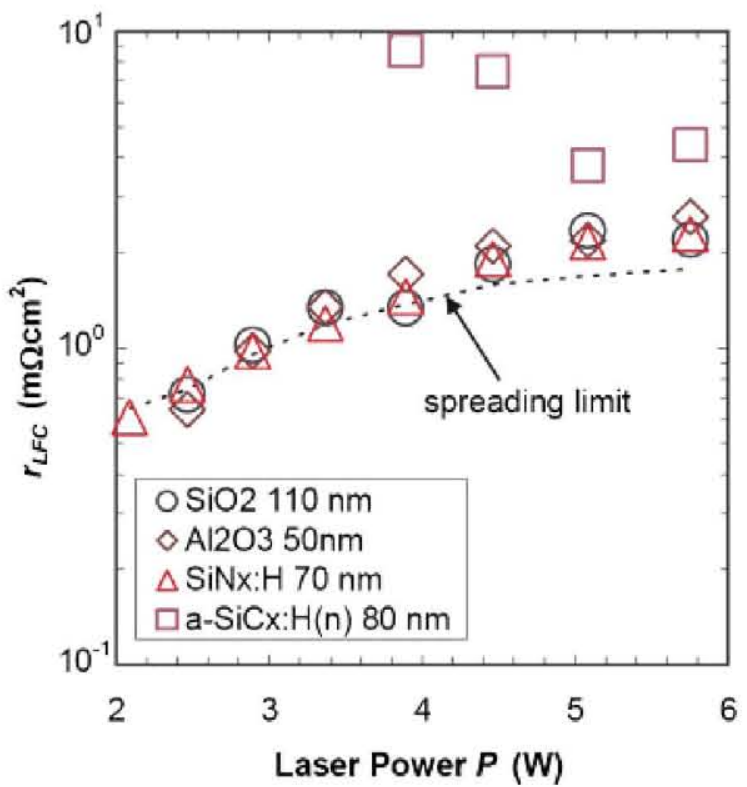

Figure 7. $r_{\mathrm{LFC}}$ versus $P$ for different passivation materials. $N_{\rho}=125$ pulses. $r_{\text {LFC }}$ has been calculated using the inner laser crater area.
Si that could compensate the aluminum doping efficiency and, hence, the quality of the contact.

A full optimization of LFC process requires knowing the number of laser pulses, $N_{\mathrm{p}}$, to minimize $r_{\mathrm{LFC}}$ for a certain laser power, as it is depicted in Figure 8. As it can be seen $r_{\text {LFC }}$ has a broad minimum for $N_{\mathrm{p}}$ of about 125 pulses when $\mathrm{SiO}_{2}, \mathrm{Al}_{2} \mathrm{O}_{3}, \mathrm{SiN}_{x} / \mathrm{H}$ materials are used. In the case of a$\mathrm{SiC}_{x} / \mathrm{H}(n)$ material, best result is achieved for $N_{\mathrm{p}}$ of about 100 pulses.

In order to understand the $r_{\text {LFC }}$ dependence on $N_{\mathrm{p}}$, we made a study of the crater morphology using a laser power $P=2.5 \mathrm{~W}$ as it is shown in Figure 9. In this case, we use the $\mathrm{SiO}_{2}$ sample; nevertheless these results can be extrapolated to the $\mathrm{SiN}_{x}$ and $\mathrm{Al}_{2} \mathrm{O}_{3}$ materials. It can be observed that for a $N_{\mathrm{p}}$ less than about 60 laser pulses (sample I in Figure 9) the electrical contact is not created corresponding to crater depths shorter than the aluminum film thickness $(2 \mu \mathrm{m})$. For more than 90 pulses, a contact is formed (sample II in Figure 9), however to get an optimal electrical contact we need $\sim 125$ pulses (sample III in Figure 9). In this case, the crater has a depth between 4 and $6 \mu \mathrm{m}$. Finally, for higher number of pulses, $r_{\text {LFC }}$ smoothly raises. In this last case, the morphological study (sample IV in Figure 9) shows that the laser beam creates a very deep conical crater with the possible contact at the bottom scarcely connected with the surrounding metal. Apparently, the dielectric film needs to be broken to obtain a good contact. Thus, a relatively high laser energy threshold is required and a crater in the silicon is unavoidable.

Furthermore, pulses in addition to what is needed to create the contact can destroy passivation at the contacts by the presence of cracks in the LFC crater due to the thermal stress in the silicon surface during the laser process stage, as it can be seen in Figure 10.

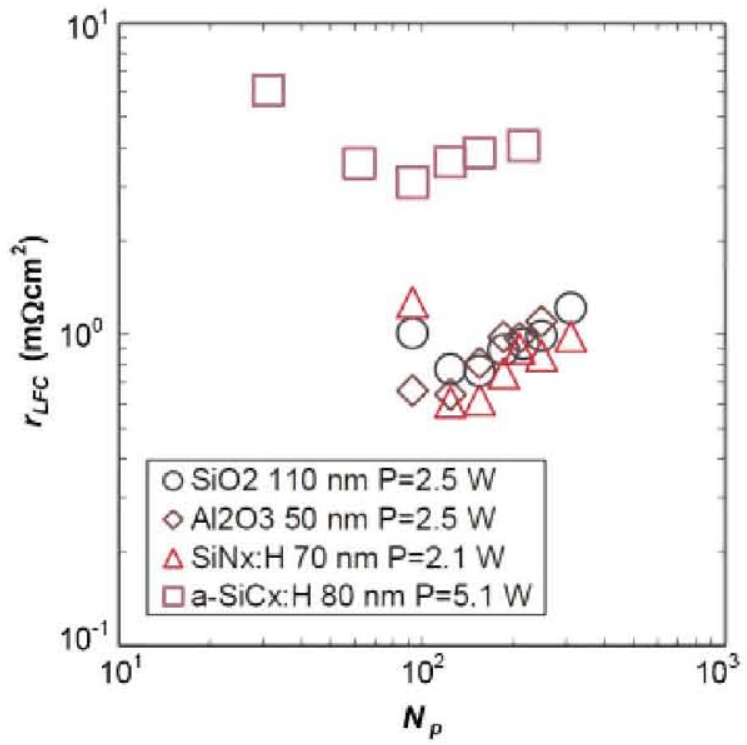

Figure 8. $r_{\text {LFC }}$ versus $N_{\rho}$ for a fixed laser power $P$ considering different passivation materials. 
(a)
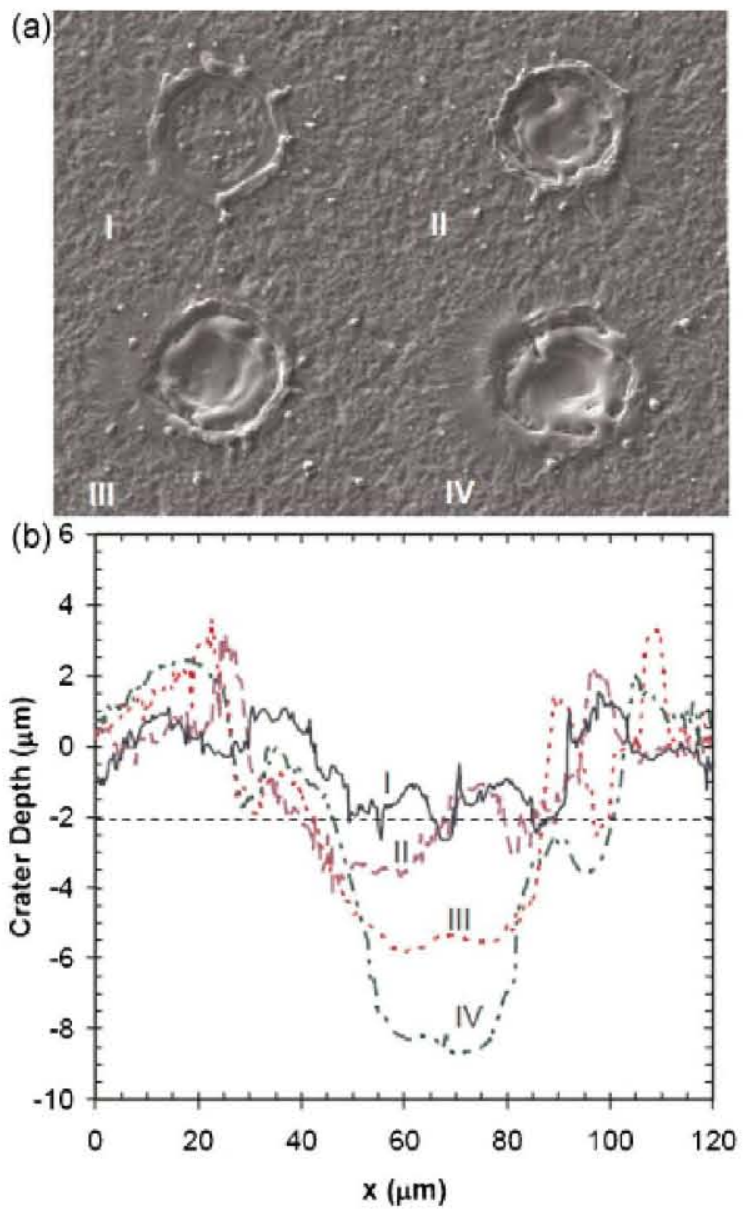

Figure 9. (a) Influence of $N_{\mathrm{p}}$ in the crater morphology. Labels I, II, III, and IV correspond with 60, 90, 125, and 180 pulses, respectively $(P=2.5 \mathrm{~W})$. (b) The crater depth for the different cases. Horizontal dashed line indicates the aluminum depth.

We performed a SEM-EDS analysis of a particular LFC point, as it is shown in Figure 11. In the center of the LFC point there is a significant percentage of aluminum in the $\mathrm{Al} / \mathrm{Si}$ alloy (percentages higher than $0.6 \%$ in the crater center). Therefore, the formation of a local BSF is possible in our LFC contacts.

Table I summarizes the optimal laser conditions for each passivation layer explored and the LFC resistance parameters. Applying equation (3), we can deduce specific contact resistance, $\rho_{\text {cef }}$, values below $0.05 \mathrm{~m} \Omega \mathrm{cm}^{2}$ except for a-SiC $\mathrm{C}_{x} / \mathrm{H}(n)$ films where values below $1.5 \mathrm{~m} \Omega \mathrm{cm}^{2}$ are obtained. Apart from this last material, the achieved contact quality is good enough to neglect it in front of the spreading resistance term $r_{\mathrm{s}}$ leading to $r_{\mathrm{LFC}}$ values proportional to substrate resistivity. Then, it is possible to extrapolate the specific LFC resistance value using any resistivity substrate. Thus, we can determine the rear contact scheme in LFC-PERC solar cells choosing an optimum contacted fraction area as a trade-off between rear passivation and base resistance.
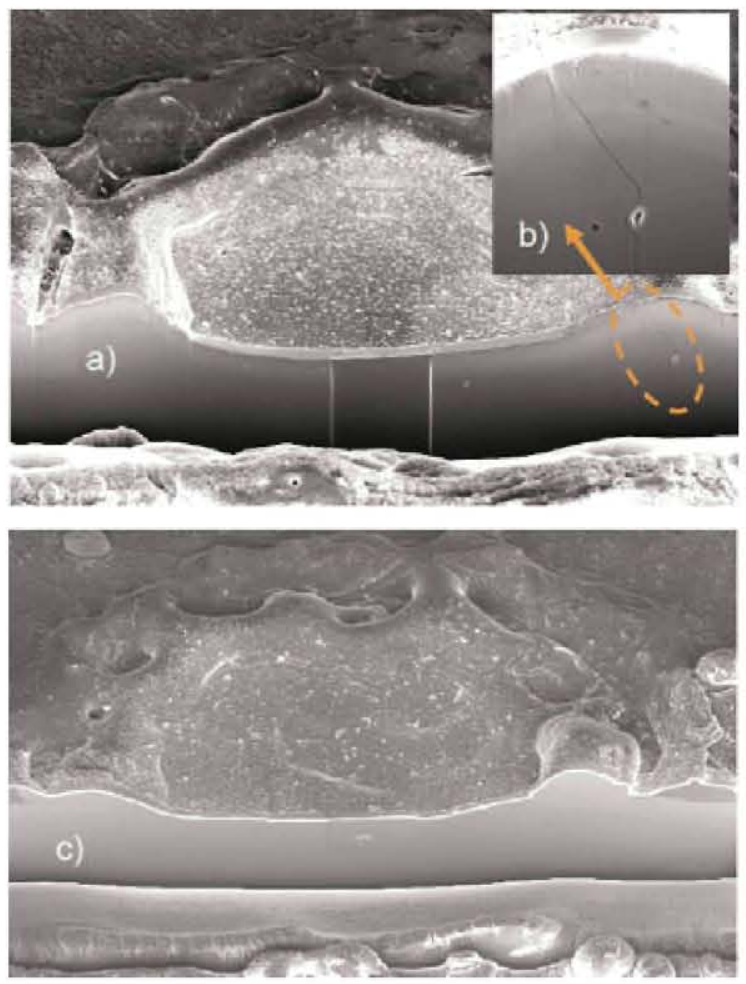

Figure 10. (a) Focused ion beam (FIB) cross-section SEM image of a LFC contact using $N_{\mathrm{p}}=150(P=2.5 \mathrm{~W})$. A $110 \mathrm{~nm} \mathrm{SiO}_{2}$ was used as a dielectric layer. Visible cracks are observed along the cross section. (b) Close view of a crack in the LFC crater. (c) FIB cross-section SEM image of a LFC contact using a lower number of pulses $N_{\mathrm{p}}=125(P=2.5 \mathrm{~W})$. In this case there are not visible cracks along the cross section.

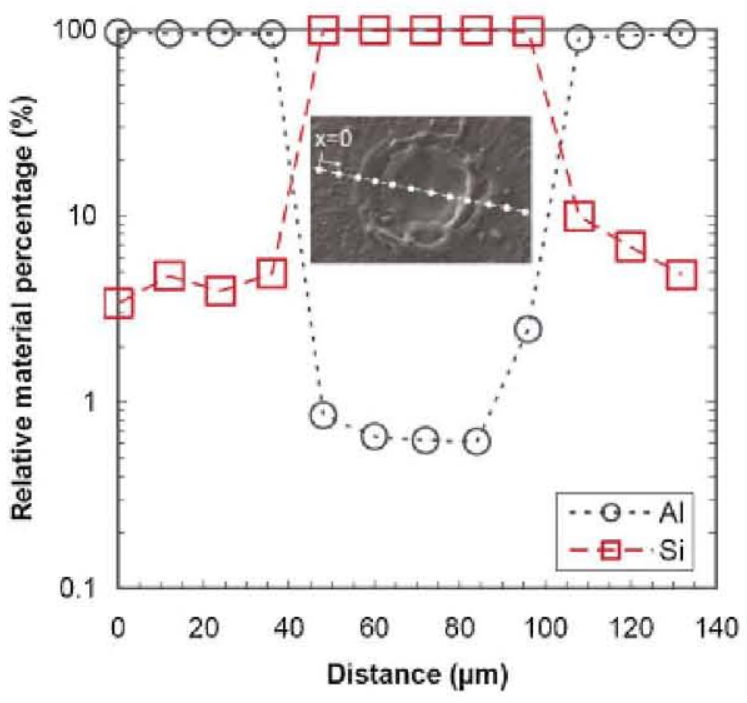

Figure 11. EDS material analysis in a LFC contact performed with 125 pulses $(2.5 \mathrm{~W})$ through a $\mathrm{SiO}_{2}$ layer. Dashed lines are guides for the eye. EDS was made in the 12 sample points shown in the inset. 
Table I. Optimal laser parameters and LFC results. The inner crater radius has been considered to calculate ${ }_{\text {LFC }}$ and $\rho_{\text {cef }}$.

\begin{tabular}{lccccc}
\hline Passivation layer & Laser Power $(W)$ & $N^{\circ}$ Pulses & Spot radius $(\mu \mathrm{m})$ & $r_{\text {LFC }}\left(\mathrm{m} \Omega \mathrm{cm}^{2}\right)$ & $\rho_{\text {cef }}\left({\mathrm{m} \Omega \mathrm{cm}^{2}}^{2}\right)$ \\
\hline $\mathrm{SiO}_{2}, 110 \mathrm{~nm}$ & 2.5 & 125 & $\sim 25$ & 0.75 & $<0.05$ \\
$\mathrm{a}-\mathrm{Si}_{\lambda} / \mathrm{H}, 80 \mathrm{~nm}$ & 5.1 & 90 & $\sim 55$ & 3.00 & $<1.5$ \\
$\mathrm{Al}_{2} \mathrm{O}_{3}, 50 \mathrm{~nm}$ & 2.5 & 125 & $\sim 25$ & 0.70 & $<0.05$ \\
$\mathrm{SiN}_{x} / \mathrm{H}, 70 \mathrm{~nm}$ & 2.1 & 125 & $\sim 20$ & 0.65 & $<0.05$ \\
\hline
\end{tabular}

\section{CONCLUSIONS}

In this work we have found laser conditions, laser power, and number of pulses, to perform optimized LFC contacts. The optimization is carried out by means of the resistance measurement of an aluminum single LFC point leading to the minimization of the specific LFC resistance, $r_{\text {LFC }}$, which takes into account the laser spot area. Optimization of laser conditions has been made using several passivation layers that are typically used in $\mathrm{c}-\mathrm{Si}$ and $\mathrm{mc}-\mathrm{Si}$ solar cell fabrication: thermal $\mathrm{SiO}_{2}$, and deposited $\mathrm{a}_{-} \mathrm{SiC}_{x} / \mathrm{H}(n)$, $\mathrm{Al}_{2} \mathrm{O}_{3}$ or $\mathrm{SiN}_{x} / \mathrm{H}$ films. Specific LFC resistances $r_{\mathrm{LFC}}$ 's about $\sim 3 \mathrm{~m} \Omega \mathrm{cm}^{2}$ in a-SiC $\mathrm{Si}_{x} / \mathrm{H}$ layers and $\sim 0.7 \mathrm{~m} \Omega \mathrm{cm}^{2}$ for the other materials, with effective specific contact resistances below 1.5 and $0.05 \mathrm{~m} \Omega \mathrm{cm}^{2}$, respectively, have been obtained. In this last case, $r_{\mathrm{LFC}}$ reaches the specific spreading resistance limit and its value is determined by the inner laser spot radius. This radius can be controlled adjusting the laser power. Furthermore, the $r_{\mathrm{LFC}}$ is proportional to the substrate resistivity allowing a fine tuning of the rear contact scheme design of a LFC-PERC solar cell.

\section{ACKNOWLEDGEMENTS}

The authors wish to thank the technical staff of the clean room Laboratory for their technical assistance in fabrication of the test LFC samples. We also would like to express a special acknowledgement to the Centre de Recerca en NanoEnginyeria CRNE for using their facilities and specially to Dr Trifon Trifonov for his help and comments to make the SEM/FIB images and EDS measurements. This work has been partially supported by the Spanish Ministry of Science and Innovation under projects CLASICO (ENE2007-67742-004-02/ALT), MICROSIL08 PSE-120000-2008-1 (FEDER funded "Una manera de hacer Europa"), AYA2009-07188-E, and TEC2008-02520.

\section{REFERENCES}

1. Chopra KL, Paulson PD, Dutta V. Thin film solar cells: An overview. Progress in Photovoltaics 2004; 12: 69-92.

2. Neuhaus DH, Münzer A. Industrial silicon wafer solar cells. Advances in Optoelectronics 2007; 2007: 1-14.
3. Cañizo C, Coso G, Sinke WC. Crystalline silicon solar module technology: Towards the $1 €$ per wattpeak goal. Progress in Photovoltaics 2009; 17: 199 209.

4. Platakis N. Mechanism of laser-induced metalsemiconductor electrical connections in MOS structures. Journal of Applied Physics 1976; 47(5): 2120 2128.

5. Schneiderlöchner E, Preu R, Lüderman R, Glunz SW. Laser-fired rear contacts for crystalline silicon solar cells. Progress in Photovoltaics 2002; 10: 29-34.

6. Hilali MM, Gee JM, Hacke P. Bow in screen-printed back-contact industrial silicon solar cells. Solar Energy Materials and Solar cells 2007; 91: 12281233.

7. Kray D, Glunz S. Investigation of laser-fired rar-side recombination properties using an analytical model. Progress in Photovoltaics 2006; 14: 195-201.

8. Glunz SW, Schneiderlöchner E, Kray D, Grohe A, Hermle M, Kampwerth H, Preu R, Willeke G. Laserfired contact silicon solar cells on $\mathrm{p}$ - and n-substrates Proceedings of the 19th EU PVSEC, Paris, France 2004; 408-411.

9. Hofmann M, Janz S, Schmidt C, Kambor S, Suwito D, Kohn N, Rentsch J, Preu R, Glunz SW. Recent developments in rear-surface passivation at Fraunhofer ISE. Solar Energy Materials and Solar cells 2009; 93: 1074-1078.

10. Glunz SW, Grohe A, Hermle M, Schneiderlöchner E, Dicker J, Preu R, Mackel H, Macdonald D, Cuevas A. Analysis of laser-fired local back surface fields using $\mathrm{n}^{+} \mathrm{np}^{+}$cells structures. Proceedings of the $3 \mathrm{rd}$ WCPEC, Osaka, Japan 2003; 1332-1335.

11. Orpella A, Martín I, Blanque S, Voz C, Sánchez I, Colina M, Molpeceres C, Alcubilla R. Optimization of laser processes in $\mathrm{n}+$ emitter formation for $\mathrm{c}-\mathrm{Si}$ solar cells. Proceedings of the 24th EU PVSEC, Hamburg, Germany 2009; 1798-1802.

12. Kerr MJ, Cuevas A. Very low bulk and $s$ urface recombination in oxidized silicon wafers. Semiconductor Science and Technology 2002; 17: 35-38.

13. Lauinger $T$, Schmidt $J$, Aberle AG, Hezel R. Record low surface recombination velocities on $1 \Omega \mathrm{cm}$ p-silicon using remote plasma silicon nitride passivation. Applied Physics Letters 1996; 68(9): 1232-1234. 
14. Ferre R, Orpella A, Muñoz D, Martin I, Recart F, Voz C, Puigdollers J, Roca P, Alcubilla R. Very low surface recombination velocity of crystalline silicon passivated by phosphorus-doped a-SiC $\mathrm{N}_{y} / \mathrm{H}(\mathrm{n})$ alloys. Progress in Photovoltaics 2008; 16: 123-127.

15. Hoex B, Heil SBS, Langereis E, Van de Sanden MCM, Kessels WMM. Ultralow surface recombination of cSi substrates passivated by plasma-assisted atomic layer deposited $\mathrm{Al}_{2} \mathrm{O}_{3}$. Applied Physics Letters 2006; 89: 042112-042112-3.
16. Denhoff MW. An accurate calculation of spreading resistance. Journal of Physics D: Applied Physics 2006; 39: 1761-1765.

17. Schwartz RJ, Lundstrom MS, Nasby RD. The degradation of high-intensity BSF solar-cell fill factors due to a loss of base conductivity modulation. IEEE Transactions on Electron Devices 1981; 28: 264 269. 